\title{
AN INTERESTING CASE OF ABDOMINAL LUMP- A LARGE, NON FUNCTIONING, EXTRA- ADRENAL PHEOCHROMOCYTOMA
}

Sreeharsha M.V1, Shivakumar $\mathrm{S}^{2}$, Shivakumar $\mathrm{M}^{3}$

\section{HOW TO CITE THIS ARTICLE:}

Sreeharsha MV, Shivakumar S, Shivakumar M. "An interesting case of abdominal lump- a large, non functioning, extra- adrenal pheochromocytoma". Journal of Evolution of Medical and Dental Sciences 2013; Vol2, Issue 32, August 12; Page: 6111-6118.

ABSTRACT: Pheochromocytoma is a tumor arising from chromaffin cells located within the adrenal medulla and in the sympathetic ganglia. It is highly vascular tumor and secretes both epinephrine and norepinephrine. 10\% of Pheochromocytoma is extra-adrenal which arise from chromaffin cells of sympathetic ganglia and can occur anywhere along the path of migration of ectodermal neural crest cells. These secrete norepinephrine exclusively and are more likely to be malignant. Majority of extra-adrenal pheochromocytoma are of functioning variety with secretion of hormones and presenting with symptoms of hypertension, sweating and weight loss. Here, we present a case of retroperitoneal, extra-adrenal pheochromocytoma of $15 \times 12 \mathrm{cms}$ size presenting as mass per abdomen without any other symptoms and with normal blood pressure, which was treated by excision of the tumor in-toto.

KEY WORDS: Pheochromocytoma; Extra-adrenal; Retroperitoneal; Non-functioning; Epinephrine; Norepinephrine.

INTRODUCTION: Pheochromocytoma is a tumor of chromaffin cells, which secrete catecholamines, predominantly norepinephrine, as well as epinephrine, and rarely dopamine. ${ }^{1}$ Incidence is estimated to be approximately 1-2/100,000 per year. ${ }^{2}$ Symptoms (classic symptom triad of episodic headaches, tachycardia, and sweating) and signs, the most common of which is hypertension, are mostly due to excessive catecholamine levels. $10 \%$ of pheochromocytoma is extra-adrenal. Extraadrenal pheochromocytoma may arise in any portion of the paraganglion system, although they most commonly occur below the diaphragm. ${ }^{3}$ Most are located within the abdomen in association with the celiac, superior mesenteric, inferior mesenteric ganglia and Organ of Zuckerkandl. Extraadrenal pheochromocytoma usually weigh 20 to $40 \mathrm{~g}$ and are $<5 \mathrm{~cm}$ in diameter. ${ }^{4}$ The diagnosis is most often confirmed by demonstrating increased catecholamine production, usually by measurement of urinary catecholamines and/or their metabolites. CT scanning is presently the imaging procedure of choice for localization and131I-MIBG scintigraphy has shown promising results. ${ }^{5}$ Complete surgical excision is the treatment of choice for primary extra-adrenal pheochromocytoma as well as recurrent or metastatic disease. Here we are presenting a case report of a large $(15 \times 12 \mathrm{cms})$, extra-adrenal, non-functioning, retroperitoneal pheochromocytoma presenting only as mass per abdomen which is an interesting and rare presentation.

CASE REPORT: A 38 year old male patient presented to our surgical OPD with mass per abdomen in the left upper quadrant since 1 year which was first noticed by a local doctor. The mass was gradually increasing in size and he did not have any other symptoms. He was not a known hypertensive. On examination his vitals were normal with blood pressure of 130/80 mmHg. Per abdomen examination revealed a mass of $13 \times 8 \mathrm{cms}$ occupying the left hypochondrium, epigastrium 
and left lumbar region. Upper border of the mass was not palpable as it was extended underneath the left costal margin. The mass was oval in shape with smooth surface, firm consistency, not moving with respiration and no mobility. Examination of rest of the abdomen and other systems were normal. Patient was admitted for further investigations. His blood investigations were normal. USG abdomen showed solid lesion of $13 \times 11 \mathrm{cms}$ with cystic areas, antero-medial to lower pole of left kidney and anterior to left psoas; possibly retroperitoneal sarcoma. CT abdomen showed heterogenous lesion of $15 \times 12 \times 10 \mathrm{~cm}$, antero-inferior aspect of left kidney, partially encasing the left renal pedicle; retroperitoneal sarcoma. CT angiogram ${ }^{6}$ was performed which showed soft tissue mass abutting antero-medial aspect of lower and mid poles of left kidney which was elevated and rotated; left renal artery and vein pushed cranially by the mass and the tumor deriving feeding arteries directly from abdominal aorta; soft tissue sarcoma. FNAC reported as malignant lesion. Thus with a diagnosis of retroperitoneal soft tissue sarcoma patient was taken up for laparotomy and on exploration a retroperitoneal solitary well encapsulated tumor of size $15 \times 12 \mathrm{~cm}$ in front of left kidney \& encasing left renal vessels, loosely adherent to surrounding structures was noted. Rest of the abdomen was normal. Tumor was dissected all around; feeding arteries ligated and tumor excised in-toto without any injury to surrounding vital structures. Intra-operative hemodynamics of the patient was stable throughout the procedure. Post-operative period was uneventful. Histopathology reported as Pheochromocytoma. VMA assay done on $9^{\text {th }}$ post-operative day was within normal limits. Patient on 1 year follow-up since then is asymptomatic and without any signs of recurrence.

DISCUSSION: Pheochromocytoma is a tumor of chromaffin cells, which secrete catecholamines, predominantly norepinephrine, as well as epinephrine, and rarely dopamine. ${ }^{1}$ Incidence is estimated to be approximately 1-2/100,000 per year. ${ }^{2}$ The majority of pheochromocytoma are sporadic, however recent studies suggest that up to $25 \%$ of cases are hereditary. ${ }^{7}$ About $10 \%$ of pheochromocytoma are malignant; this goes up to $33 \%$ in extra-adrenal pheochromocytoma. Symptoms (classic symptom triad of episodic headaches, tachycardia, and sweating) and signs, the most common of which is hypertension, are mostly due to excessive catecholamine levels. $10 \%$ are bilateral. Solitary lesions inexplicably favor the right side. Although pheochromocytoma may grow to large size ( $>3 \mathrm{~kg}$ ), most weigh $<100 \mathrm{~g}$ and are $<10 \mathrm{~cm}$ in diameter. Pheochromocytoma is highly vascular.

Extra-adrenal pheochromocytoma may arise in any portion of the paraganglion system, although they most commonly occur below the diaphragm. Most are located within the abdomen in association with the celiac, superior mesenteric, inferior mesenteric ganglia and Organ of Zuckerkandl. Although the traditional teaching has been that $10 \%$ of all pheochromocytoma are at extra-adrenal sites, this may be an underestimation. Extra-adrenal pheochromocytoma probably represents at least $15 \%$ of adult and $30 \%$ of childhood pheochromocytomas. ${ }^{8}$ It most commonly occurs in the 2 nd and 3rd decade of life with a slight male preponderance. This is in contrast to adrenal pheochromocytoma, which typically are diagnosed in the 4th and 5th decades with a slight propensity for women. ${ }^{3}$ The collection of paraganglia located anterolaterally to the distal abdominal aorta between the origin of the inferior mesenteric artery and the aortic bifurcation is called the organ of Zuckerkandl. These paraganglia are accessory tissues of the autonomic nervous system and function as the dominant source of catecholamine production in the fetus until they regress after age 
3 years. Failure of involution of chromaffin tissue leads to the development of paragangliomas at these sites. Eighty-five percent of extra-adrenal pheochromocytoma is located in the retroperitoneum, usually arising from the organ of Zuckerkandl. Less common sites reported include the bladder, thorax, neck, and pelvis. ${ }^{9}$ Additionally, extra-adrenal pheochromocytoma tend to demonstrate multicentricity in $15 \%$ to $24 \%$ of cases.

A classification system for extra-adrenal pheochromocytoma proposed by Glenner and Grimley ${ }^{10}$ in 1974 divided the tumors into four groups based on location: branchiomeric, intravagal, aortico sympathetic, and visceroautonomic. The branchiomeric and intravagal tumors occur in the head and neck, are rarely functional, and generally stain negative for chromaffin. The aortico sympathetic group is found along the length of the aorta, between the renal arteries, around the iliac bifurcation, and includes the organ of Zuckerkandl. The visceroautonomic division occurs in association with blood vessels or visceral organs like the bladder. The latter two groups tend to be functional and usually are chromaffin positive.

Extra-adrenal pheochromocytoma usually weigh 20 to $40 \mathrm{~g}$ and are $<5 \mathrm{~cm}$ in diameter. Although extra-adrenal pheochromocytoma can be nonfunctional, the majority of extra-adrenal pheochromocytoma occurring below the diaphragm is functional with the symptoms related to the excessive secretion of catecholamines, namely norepinephrine. Functional tumors tend to be smaller when detected because of the symptoms it is capable of producing as opposed to nonfunctional tumors, which can be larger when diagnosed. ${ }^{11,12}$ Symptoms from extra-adrenal pheochromocytoma may also result from tumor compression of adjacent structures.13-16 Also, extra-adrenal pheochromocytoma located near the renal hilum have been found to cause renal artery stenosis in $75 \%$ of cases. Because of the variety of clinical manifestations and nonspecific physical findings, the diagnosis of a pheochromocytoma, and especially those located outside of the adrenal, requires a particularly high index of suspicion. The diagnosis of a malignant extra-adrenal pheochromocytoma is commonly made on the basis of recurrence and the development of metastasis to lymph nodes or to other organs. Some authors include local invasion as a feature of malignancy as well. One review suggests that $41 \%$ of extra-adrenal pheochromocytoma arising from the organ of Zuckerkandl were malignant based on criteria of metastases and local invasion. However, specific histological features help to differentiate adrenal pheochromocytoma with a potential for biologically aggressive behavior from those that behave in a benign fashion. Among the features that suggest a malignant course are large tumor size ( $>5 \mathrm{cms}$ ) and an abnormal DNA ploidy pattern (aneuploidy, tetraploidy). ${ }^{17,18}$ Common metastatic sites include bone, liver, and lymph nodes.

The diagnosis is most often confirmed by demonstrating increased catecholamine production, usually by measurement of urinary catecholamines and/or their metabolites. CT scanning is presently the imaging procedure of choice for localization. ${ }^{19}$ Imaging studies to evaluate for extra-adrenal pheochromocytoma include CT, MRI, and (131) I-labeled metaiodobenzylguanidine scintigraphy.4,20,21 Preoperative pharmacologic preparation, attentive intraoperative monitoring, and aggressive surgical therapy have important roles in achieving successful outcomes. ${ }^{8}$ Recent reports suggest that a laparoscopic approach, along with intraoperative ultrasound, can safely remove these tumors. Surgical resection of the tumor is the treatment of first choice, either by open laparotomy or laparoscopy. ${ }^{22-28}$ Given the complexity of perioperative management, and the potential for catastrophic intra and postoperative complications, such surgery should be performed only at centers experienced in the management of 
this disorder. In addition to the surgical expertise that such centers can provide, they should also have the necessary endocrine and anesthesia resources. Complete surgical excision is the treatment of choice for primary extra-adrenal pheochromocytoma as well as recurrent or metastatic disease. Extra-adrenal pheochromocytoma is more likely to recur and to metastasize than their adrenal counterparts, making lifelong follow-up with annual determinations of catecholamine production essential. Chemotherapy and radiotherapy have not shown good response rate in extra-adrenal pheochromocytoma but have a role in adrenal phaeochromocytomas. ${ }^{8}$

Our case was an adult male presenting as mass per abdomen only and being diagnosed preoperatively as retroperitoneal sarcoma because of absence of characteristic symptoms of functional pheochromocytoma and lack of characteristic cells on FNAC. There was no metastasis on preoperative imaging and even on laparotomy; it was a well encapsulated tumor without any local invasion. Literature review ${ }^{5,18}$ suggests that extra-adrenal pheochromocytoma $>5 \mathrm{cms}$ are usually of functional type and also having more chances of being malignant. But in our case, though the size of the tumor was $15 \times 12 \mathrm{cms}$, it was non-functional and benign in nature, making it an interesting case.

CONCLUSION: In conclusion, diagnosis of non-functional, extra-adrenal pheochromocytoma requires high degree of suspicion, even more if it is in retroperitoneal plane, as it can mimic retroperitoneal sarcoma. A good pre-operative imaging investigation to look for extent and distant metastasis will be of good help in planning for surgical excision. A thorough work-up for functional aspect of pheochromocytoma is must for adequate preparation of patient for surgery and to manage the patient well both intra and post-operatively. And finally, surgical excision is the best treatment option for extra-adrenal pheochromocytoma.

\section{REFERENCES:}

1. Sweeney, Ann T, Griffing, George T. Pheochromocytoma. August 2, 2011; eMedicine.medscape.com.

2. Melmed. Clinical presentation of pheochromocytoma and paraganglioma. Williams textbook of Endocrinology. 12 $2^{\text {th }}$ edition; 2011.

3. Whalen RK, Althausen AF, Daniels GH. Extra-adrenal pheochromocytoma. J Urol. 1992 Jan; 147(1):1-10.

4. Disick GI, Palese MA. Extra-adrenal pheochromocytoma: diagnosis and management. Curr Urol Rep. 2007 Jan; 8(1):83-8.

5. Pan DL, Li HZ, Zeng ZP, Li F, Cui QC. Clinical diagnosis and treatment of nonfunctioning pheochromocytoma in 14 patients. Chin Med Sci J. 2005 Jun; 20(2):126-8.

6. H. P. Jander. Angiography of a Clinically Nonfunctioning Pheochromocytoma. JAMA. 1976; 235(7):707.

7. Pacak K, Linehan WM, Eisenhofer G, et al. Recent advances in genetics, diagnosis, localization and treatment of pheochromocytoma. Ann Intern Med 2001; 134:315-20.

8. Grant IS, Disick and Michael A. Palese. Extra-adrenal Pheochromocytoma: Diagnosis and Management. Current Urology Reports 2007; 8:83-88.

9. Salanatri J, Smith P, Sclicht S. Multifocal malignant extra adrenal paragangliomas of the organ of Zuckerkandl and urinary bladder. Austrasl Radiol 2001; 45:229-232. 
10. Glenner GG, Grimley PM. Tumors of the extra-adrenal paraganglion system. In Atlas of Tumor Pathology (2nd series). Washington DC: Armed Forces Institute of Pathology; 1974.

11. Amit Agarwal, Sushil Gupta, Anand Kumar Mishra, Nikhil Singh, Saroj K Mishra. Normotensive Pheochromocytoma, Institutional experience. World J. Surg. Sep 2005; 29(9):35-39.

12. Dulhy RG, Lawrence JE, Williams GH, Larsen PR, Kronenberg HM, Melmed S, Polonsky KS. Endocrine Hypertension. In Williams Textbook of Endocrinology. 12 th Edition; 2011.

13. Hwang JJ, Shoaf G, Uchio EM, et al. Laparoscopic management of extra-adrenal pheochromocytoma. J Urol 2004; 171:72-76.

14. Yadav S, Singh SK, Sharma SK, et al. Extra-adrenal pheochromocytoma: A cause of ureteral obstruction. J Urol 2000; 163:264-88.

15. Blecha M, Galanopolous C, Dharkar D, et al. Massive organ of Zuckerkandl inducing small bowel obstruction. J Am Coll Surg 2005; 201:480-481.

16. Stevenson S, Ramani V, Nasim A, et al. Extra-adrenal pheochromocytoma: an unusual cause of deep vein thrombosis. J Vasc Surg 2005; 42:570-572.

17. Goldfarb DA, Novick AC, Bravo EL, et al. Experience with extra-adrenal pheochromocytoma. J Urol 1989; 142:931-936.

18. Scott H, Halter S. Oncologic aspects of pheochromocytoma: the importance of follow-up. Surgery 1984; 96:1061-1066.

19. Alderazi Y, Yeh M, Robinson B, et al. Pheochromocytoma: current concepts. Med J Aust 2005; 183:201-204.

20. VanErkel AR, Van Gils APG, Lepuin M, Kruitwagen C, Bloem JL, Falke TH. CT and MR distinction of adenomas and non adenomas of the adrenal gland. J Comput Asist Tomogr 1994; 18(13):432-8.

21. Fujita A, Hyodoh $H$, Kawamura $Y$, et al. Use of fusion images of I-131 metaiodobenzylguanidine, SPECT and magnetic resonance studies to identify a malignant pheochromocytoma. Clin Nucl Med 2000; 25:440-442.

22. Vargas H, Kavoussi L, Bartlett D, et al. Laparoscopic adrenalectomy: a new standard of care. Urology 1997; 49:673-678.

23. Janetschek G, Finkenstedt G, Gasser R, et al. Laparoscopic surgery for pheochromocytoma: adrenalectomy, partial resection, excision of paragangliomas. J Urol 1998; 160:330-334.

24. Lombardi C, Raffaelli M, De Crea C, et al. Pheochromocytoma: role of preoperative diagnosis in the assessment of malignancy risk and in the choice of surgical approach. Suppl Tumori 2005; 4:S211.

25. Tagaya N, Suzuki N, Furihata T, et al. Laparoscopic resection of a functional paraganglioma in the organ of Zuckerkandl. Surg Endosc 2002; 16:219.

26. Mithani SK, Marohn MR, Freischlag JA, et al. Laparoscopic resection of a paraganglioma of the organ of Zuckerkandl in a patient with a carotid body tumor. Am Surg 2006; 72:55-59.

27. Walz M, Peitgen K, Neumann H, et al. Endoscopic treatment of solitary, bilateral, multiple, and recurrent pheochromocytoma and paragangliomas. World J Surg 2002; 26:1005-1012.

28. Kercher KW, Heniford BT, Marroum MC, et al. Laparoscopic intraoperative ultrasonic localization and resection of an extra-adrenal pheochromocytoma. J Laparoendosc Adv Surg Tech 1999; 9:511-515. 


\section{CASE REPORT}

\section{PHOTOGRAPHS:}

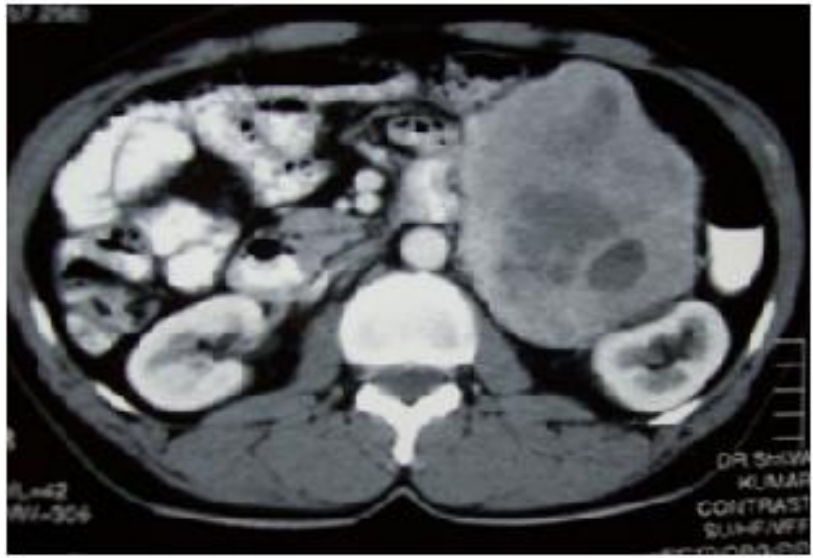

Fig. 1: CT scan picture showing heterogenous mass lesion, antero-inferior aspect of left kidney.

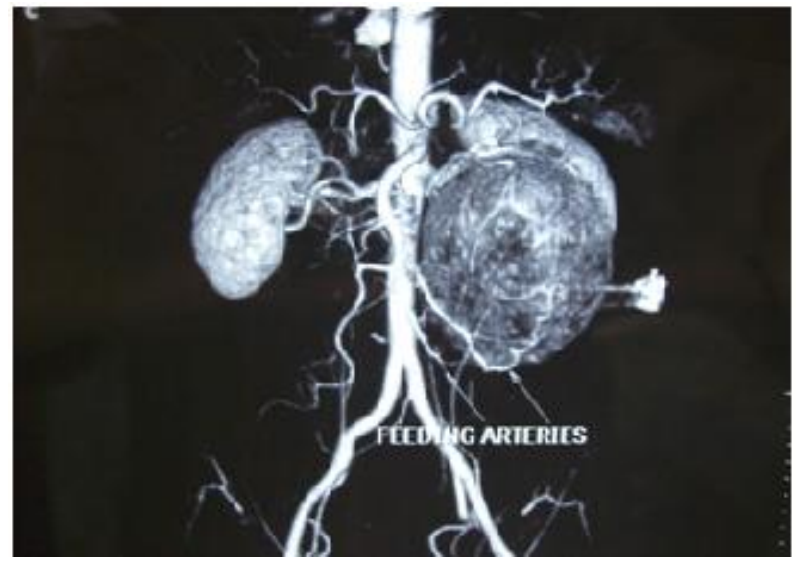

Fig. 2 CT angiogram showing soft tissue mass abutting antero-medial aspect of lower and mid poles of left kidney which was elevated and rotated; left renal artery and vein pushed cranially by the mass and feeding arteries to the mass coming from abdominal aorta.

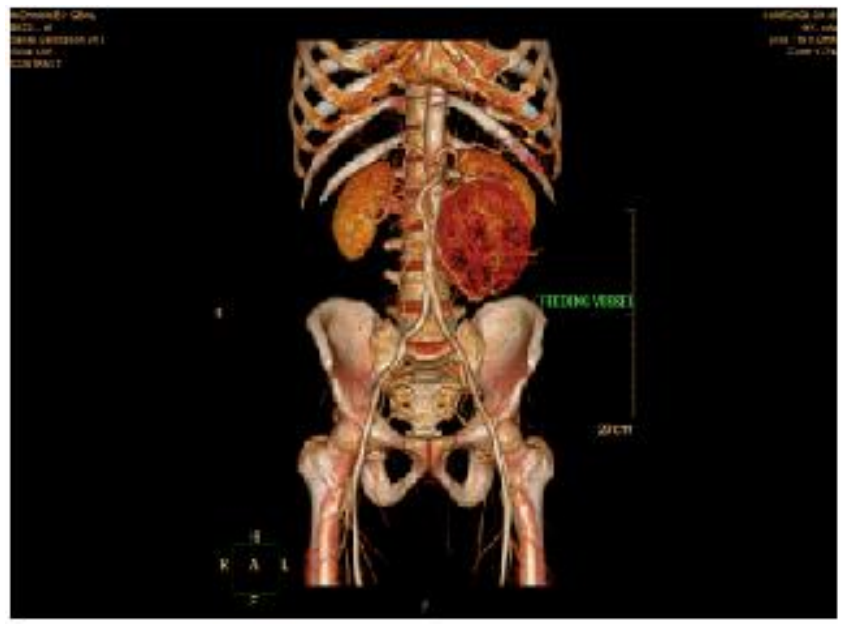

Fig. 3: CT angiogram colour photograph showing mass abutting the left kidney and its feeding artery. 


\section{CASE REPORT}

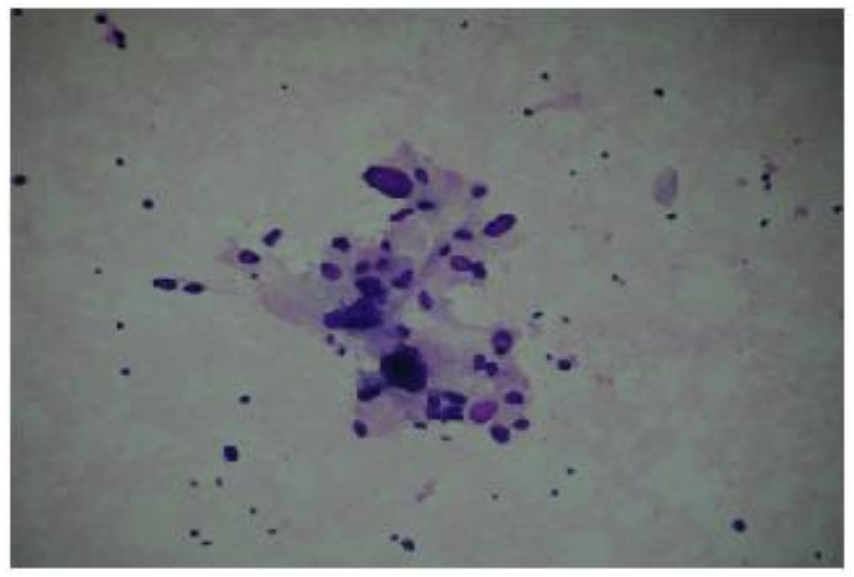

Fig. 4 FNAC reported as malignant lesion

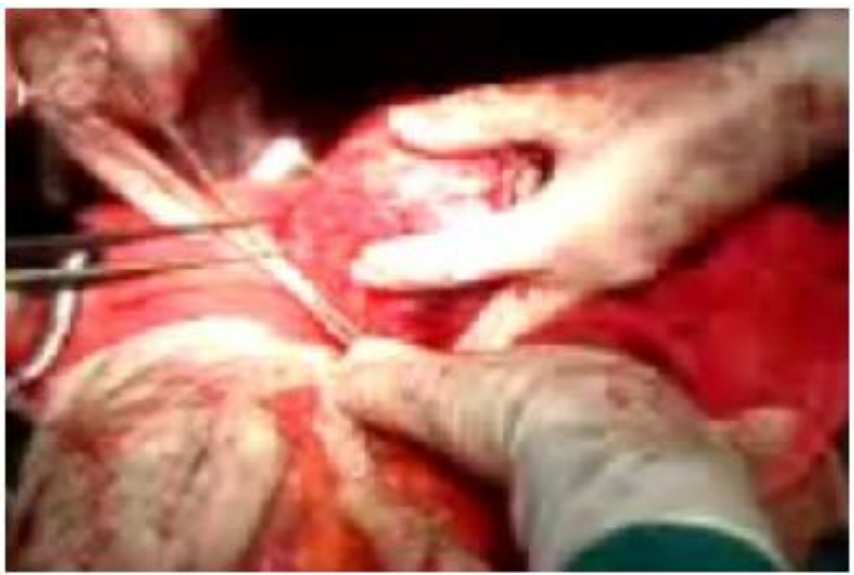

Fig. 5 Intra-operative photograph showing the dissection of encapsulated tumor by ligating the feeding artery.

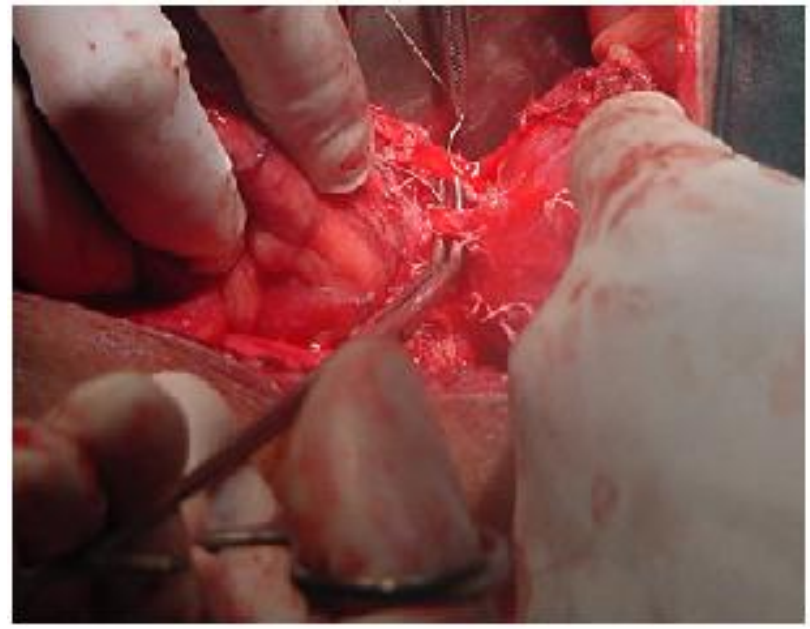

Fig. 6 Intra-operative photograph showing ligation of feeding artery to the tumor 


\section{CASE REPORT}

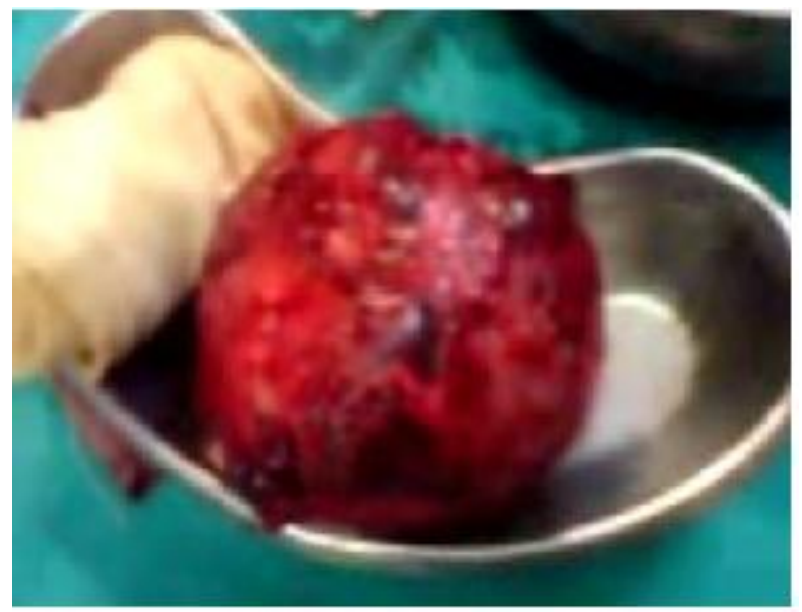

Fig. 7 Photograph of specimen of encapsulated tumor excised in-toto

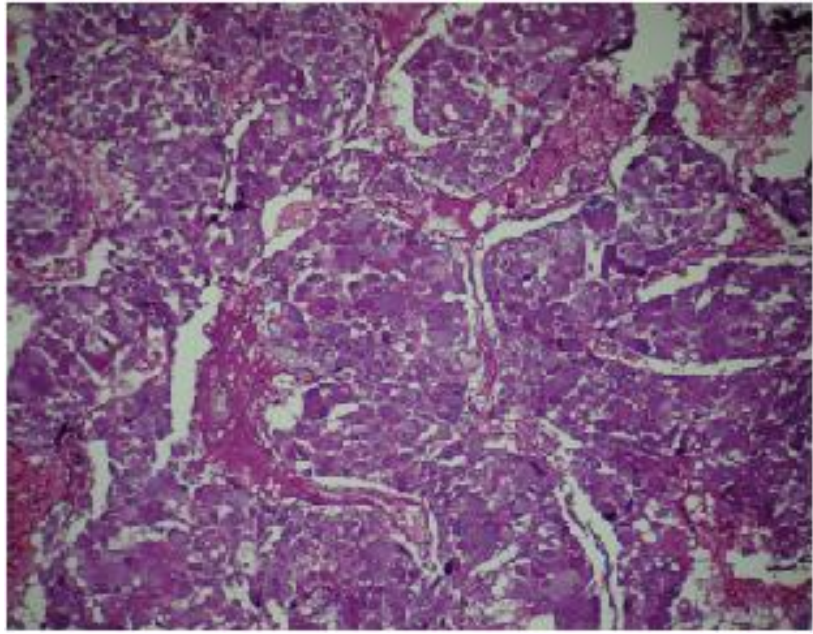

Fig. 8 Histopathological slide reported as Pheochromocytoma

\section{AUTHORS:}

1. Sreeharsha M.V.

2. Shivakumar S.

3. Shivakumar M.

\section{PARTICULARS OF CONTRIBUTORS:}

1. Assistant Professor, Department of Surgery, J.S.S. Medical College, Mysore.

2. Associate Professor, Department of Surgery, J.S.S. Medical College, Mysore.

3. Professor, Department of Surgery, J.S.S. Medical College, Mysore.
NAME ADRRESS EMAIL ID OF THE CORRESPONDING AUTHOR:

Dr. Sreeharsha M.V., Assistant Professor, Department of Surgery, J.S.S. Medical College Hospital, Ramanuja Road, Mysore - 570004, Karnataka. Email-drharsha_mv@rediffmail.com

Date of Submission: 29/07/2013. Date of Peer Review: 03/08/2013. Date of Acceptance: 08/08/2013. Date of Publishing: 12/08/2013 